\title{
Review Article \\ Review of Factors Controlling Skid Resistance at Tire-Pavement Interface
}

\author{
Abhinav Kumar $(\mathbb{D})$ and Ankit Gupta \\ Department of Civil Engineering, Indian Institute of Technology (BHU), Varanasi, India \\ Correspondence should be addressed to Ankit Gupta; ankit.civ@iitbhu.ac.in
}

Received 22 May 2021; Revised 12 July 2021; Accepted 24 September 2021; Published 5 October 2021

Academic Editor: Yi Zhang

Copyright (c) 2021 Abhinav Kumar and Ankit Gupta. This is an open access article distributed under the Creative Commons Attribution License, which permits unrestricted use, distribution, and reproduction in any medium, provided the original work is properly cited.

\begin{abstract}
Road safety is of prime importance for pavement engineers and maintenance authorities. Pavement resistance to skidding of the vehicle has long been recognized as one of the leading parameters governing road safety and driving comfort, especially in wet weather conditions. The knowledge of skid resistance offered by pavement surface is very valuable information for road safety enhancements. Skid resistance is defined as the force developed when a tire that is prevented from rotation slides along the pavement surface. Evaluation of skid resistance over time and estimation of factors influencing it are important for pavement maintenance and rehabilitation planning. This paper presents a state-of-the-art review of various research works carried out for assessing critical parameters like surface texture, tire tread, rain intensity, temperature, loading condition, tire inflation pressure, and pavement type which control skid resistance of asphalt pavement at tire-road interface significantly. First, a brief overview of skid resistance and its importance in asphalt pavement is provided. Then, critical parameters influencing skid resistance are identified and reviewed more elaborately. Furthermore, the key relationship between skid resistance and various controlling parameters is reviewed and presented for a better understanding of skid variation analysis. Finally, a general discussion on skid resistance governing factors, their relative importance in maintaining safety and pavement performance, the complexity involved in computation, and established relationships with skid resistance is briefly summarized.
\end{abstract}

\section{Introduction}

Skid resistance is the force developed when a tire that is prevented from rotation slides over the pavement surface. It has been the key to enhancing driving safety and avoiding potential crashes $[1,2]$. Previous studies on skid resistance highlight the relation between skid resistance of the pavement and traffic accidents. The lower the skid resistance of the pavement is, the higher the accident rate is. There is a drastic increase in accident risk as skid resistance lowers below a certain threshold. Therefore, it is important to understand the fundamental mechanism of tire-pavement interaction. The evaluation methodology of pavement surface characteristics, like skid resistance and parameters affecting it, has been consistently upgrading in due course of time. Estimating key parameters and controlling skid resistance practically in field are very tedious, time- consuming, costly, and labour-intensive. Additionally, evaluating these parameters and establishing a relationship with skid resistance in laboratories lack accuracy in absence of actual field conditions. To overcome these difficulties and make assessment easier, researchers have developed various prediction models based on finite element method, discrete element method, and molecular dynamics simulation at an atomistic level. Statistical prediction and empirical relations have also been proposed to predict the variation of skid resistance subjected to variable field conditions with better reliability and accuracy. Depending upon the location, climatic condition, method of construction, and materials used in construction, factors affecting skid resistance vary significantly. Although various parameters related to the pavement surface, tire material, loading condition, and environmental conditions affecting skid resistance have been identified and reported in various research studies, a few of 
them like surface texture (micro and macro), tire tread pattern, rain intensity, and environmental temperature have been observed to be a critical parameter which alone influences skid resistance significantly and has been given due consideration and much more attention than other parameters in past studies. Mean profile depth (MPD) and mean texture depth (MTD) are the most common parameters used for the characterization of pavement surface macrotexture. The commonly used sand patch method defines the MTD as the ratio of volume to the total area covered, whereas the MPD is defined as the average of all the mean segment depths of all the segments of the profile [3]. It measures the height of the highest peaks above the mean level [4]. Pratico and Vaiana [5] established the relationship between mean texture depth and mean profile depth of asphalt pavement and found that MPD and sand patch texture measure different properties, and linear correlations seem not to represent complexity and dissimilarity effectively.

\section{Skid Resistance}

Skid resistance is the force developed when a tire that is prevented from rotating slides along the pavement surface. Pavement friction is the result of tire-pavement interaction. The friction force developed at the tire-pavement contact zone is called skid resistance [6]. Skid resistance is a measure of safety for driving on the road surface and has a great role in reducing accidents especially in wet weather conditions [7]. According to a report, approximately $14 \%$ of the total fatal road accidents occur in wet weather conditions [8-10]. Kuttesch [11] quantified the relationship between skid resistance and wet weather accidents and reported that the wet accident rate is on average $44 \%$ higher for sites with skid number less than or equal to 30 than for sites with skid number greater than 30. Saplioglu et al. [12] investigated the effect of skid resistance on accidents that occurred at an urban intersection and found an increase of $70 \%$ in accident rate when the skid resistance number reduces from 53.5 to 38 . The wet accident rate is inversely proportional to the skid resistance for all kinds of carriageways [13, 14]. Skid resistance is influenced by various factors of pavement surface, tire characteristics, and environmental-related parameters. Depending upon the rotational speed of the wheel and surface characteristics of the road surface, once the maximum friction is reached, the wheel may start skidding. A direct impact of skidding is a drastic loss of braking efficiency and steering capability of the vehicle which may lead to damage of the pavement and, in extreme cases, may result in human causalities. This problem gets further exaggerated in presence of water on the pavement surface due to the phenomena of hydroplaning (when tire rolls on wet pavement at high speed such that hydrodynamic forces uplift the tire). Skid resistance explains the contribution of a road surface to the development of friction at the tire-pavement interface. Unfortunately, with the time and traffic, the asperities of the road surface keep on reducing and, as a consequence, skid resistance diminishes as well [15]. As shown in Figure 1, friction originates primarily from the interaction of the asperities of the pavement surface with the morphological characteristics of the vehicular tire.

Pavement friction is a result of the complex interplay between two principle frictional force components, adhesion and hysteresis, as shown in Figure 2. Adhesion results from the small-scale interlocking of tire rubber and pavement surface, while hysteresis results from the energy loss due to bulk deformation of tire rubber [16]. Adhesion is the result of interface shear and is significant for a smooth surface. When a tire compresses against the pavement surface, the stress distribution causes the deformation energy to be stored within the rubber. As the tire relaxes, part of the stored energy is recovered while the other part is lost in the form of heat (hysteresis), which is irreversible. That loss leaves a net frictional force to help stop the forward motion.

2.1. Skid Resistance and Texture Measurements. It is necessary to evaluate accurately the skid resistance of a pavement surface to prevent accidents and ensure safe highway operation. Reliable pavement skid resistance measurement can be obtained from friction measuring vehicles in the field or by laboratory measurement techniques. Table 1 presents a brief introduction of the skid resistance measurement device used in the laboratory, and Table 2 highlights a brief discussion on measuring methods of skid resistance in the field.

In an effort to develop a highly conversing model for the performance of skid resistance, it is evident that it correctly quantifies every parameter affecting skidding on the pavement surface. Pavement surface textural characteristics have a significant contribution to the control of skid resistance and shall be measured by correctly adopting a suitable methodology. A simplified approach to assess the pavement surface micro- and macrotexture was considered [26]. Miniaturised macro- and microtexture tests prove to be reliable tools to optimise texture design. Table 3 presents various pavement surface texture measurement techniques, their measurement principle, advantages, and disadvantages in brief.

\section{Factors Affecting Skid Resistance}

Pavement shall be designed such that minimum skid resistance available for safe driving should be met throughout its design life. At the time of design itself due considerations shall be given in assessing key factors controlling skid resistance so as to minimize the risk associated.

Factors affecting skid resistance can be grouped into four major categories: pavement surface characteristics, vehicle operating parameters, tire properties, and environmental conditions. Table 4 lists factors comprising each category. Since every factor listed here plays an important role in defining pavement skid resistance, skid resistance shall be viewed as a process rather than an inherent property of the pavement. It is only when all these factors are correctly evaluated and specified that skid resistance takes on a definite value. The more critical factors are shown in italics in Table 4 and are more elaborately discussed in the subsequent section. Among these parameters, those which are 


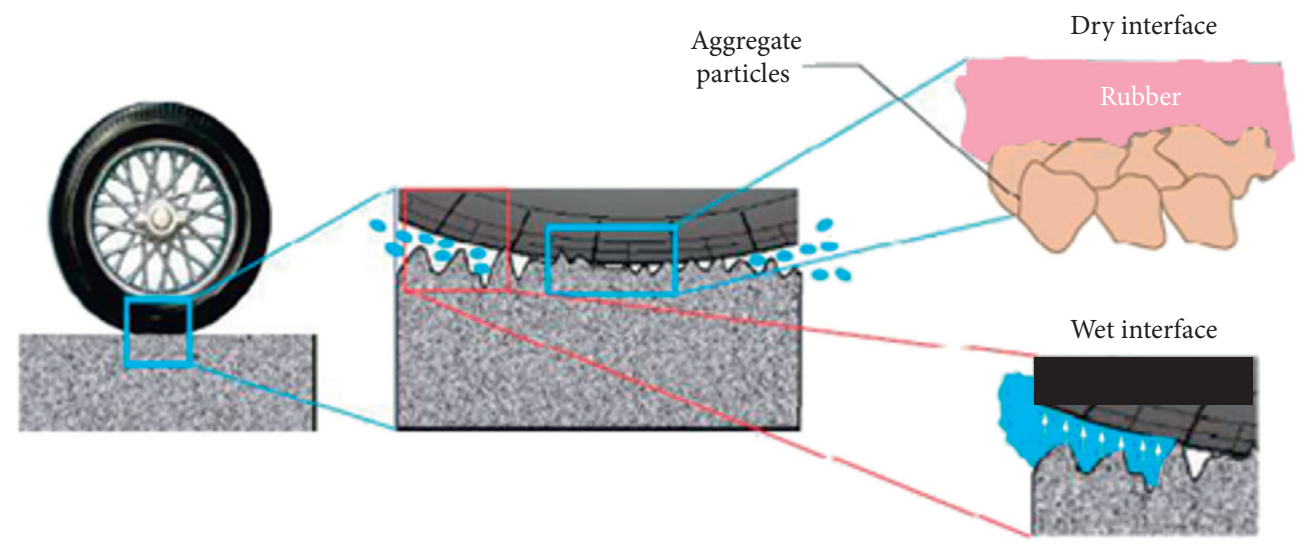

FIGURE 1: Skid resistance and hydrodynamic stresses at tire-pavement interface [15].

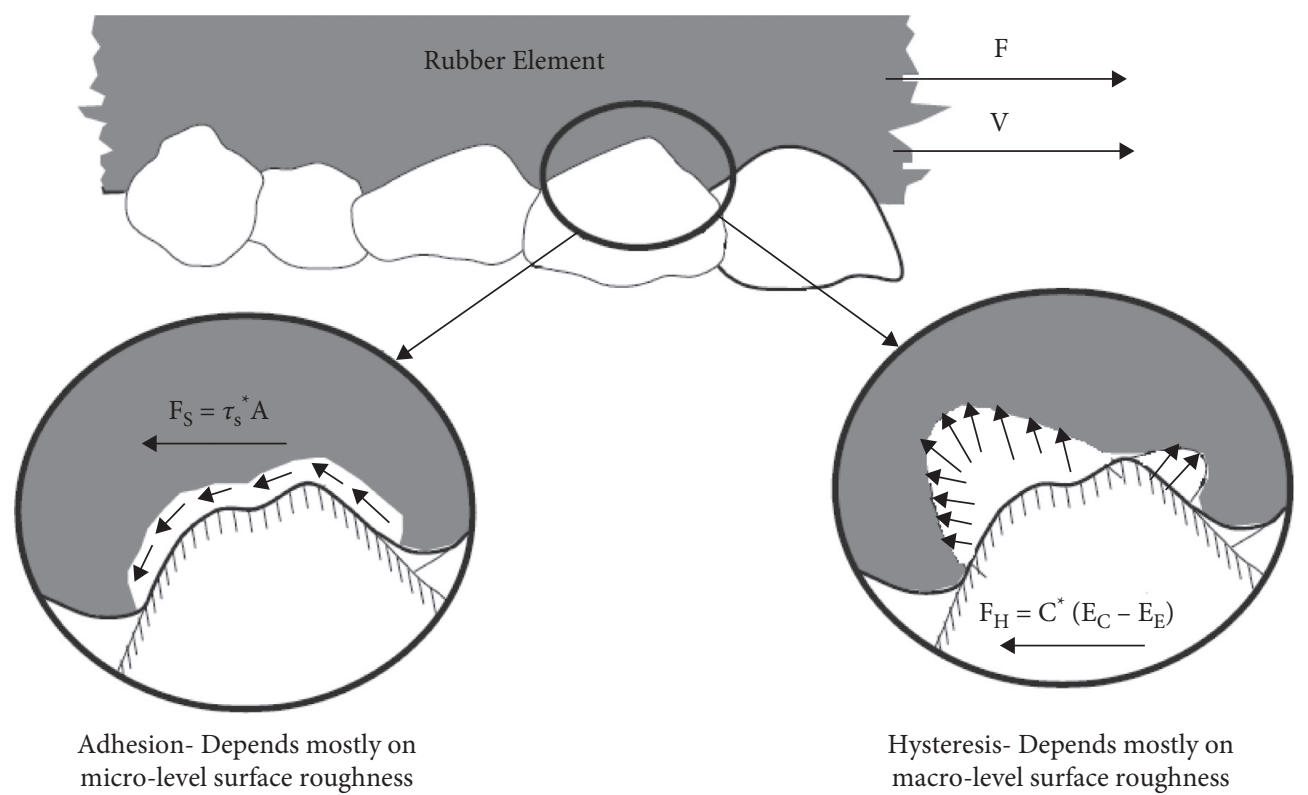

FIGURE 2: Schematics of adhesion and hysteresis [17].

TABLE 1: Direct measuring methods of pavement skid resistance in laboratories [18-21].

Device Measurement principle and measuring condition

British pendulum test (BPT)

Dynamic friction tester (DFT)

Wehner/Schulze (W/S)

Tire-pavement dynamic friction analyser (TDFA)
Impact manner: As the rubber pad swipes on the pavement surface, the tire-pavement friction will resist the swinging tendency of the pendulum, and the reduced kinetic energy of the pendulum will be converted to potential energy when the pendulum gets the maximum height, which is represented by BPN. Contact area $\left(\mathrm{mm}^{2}\right): 9601.2$, measured speed $(\mathrm{km} / \mathrm{h}): 10$.

Impact manner: Rubber pads on the rotating plate are brought into contact with the testing surface, as the plate is set to reach the target speed. Afterwards, the speed of pads will be slowed down to zero owing to the friction in the contacting interface, with the friction coefficient measured at a given speed. This device can be used both in the laboratory and in the field. Contact area $\left(\mathrm{mm}^{2}\right)$ : 64242.4, measured speed $(\mathrm{km} / \mathrm{h}): 10-80$, contact pressure (MPa): 0.15 .

Impact manner: In the phase of friction testing, rotation beads are accelerated to $100 \mathrm{~km} / \mathrm{h}$ initially, and then water is sprayed on the specimen surface. Then, the beads are lowered onto the test surface, and the friction coefficient is recorded. Contact area $\left(\mathrm{mm}^{2}\right): 39760.8$, measured speed $(\mathrm{km} /$ h): 60 , contact pressure (MPa): 0.2 .

Impact manner: Driven by the engine, a pavement specimen is rotated, driving the rotation of upper tires. The friction force and upper loading can be measured in real time in this period for the calculation of the friction coefficient. Contact area $\left(\mathrm{mm}^{2}\right): 49087.4$, measured speed $(\mathrm{km} / \mathrm{h})$ : 
TABLE 2: Summary of skid resistance measuring devices in the field [22-25].

\begin{tabular}{|c|c|c|c|}
\hline Device & $\begin{array}{l}\text { Measurement } \\
\text { principle }\end{array}$ & Main parameters & Tire \& wheel load \\
\hline ADHERA & $\begin{array}{l}\text { Longitudinal friction } \\
\text { coefficient }\end{array}$ & $\begin{array}{l}\text { Water film thickness: } 1.0 \mathrm{~mm} \text {, measurement speed: } 40,60 \text {, } \\
\qquad 90,120 \mathrm{~km} / \mathrm{h} \text {; it measures macrotexture }\end{array}$ & $\begin{array}{l}\text { PIARC smooth profile tire }(180 \mathrm{kPa}) \text {, } \\
\text { wheel load: } 2500 \mathrm{~N}\end{array}$ \\
\hline BV11 & $\begin{array}{l}\text { Longitudinal friction } \\
\text { coefficient }\end{array}$ & $\begin{array}{c}\text { Slip ratio: } 17 \% \text {, water film thickness: } 0.5-1.0 \mathrm{~mm} \text {, } \\
\text { measurement speed: } 70 \mathrm{~km} / \mathrm{h}\end{array}$ & $\begin{array}{c}\text { Trelleborg type T49 tire }(140 \mathrm{kPa}) \\
\text { wheel load: } 1000 \mathrm{~N}\end{array}$ \\
\hline RoadSTAR & $\begin{array}{l}\text { Longitudinal friction } \\
\text { coefficient }\end{array}$ & Slip ratio: $18 \%$, water film thickness & $\begin{array}{l}\text { PIARC tire with tread, wheel load: } \\
\qquad 3500 \mathrm{~N}\end{array}$ \\
\hline ROAR DK & $\begin{array}{l}\text { Longitudinal friction } \\
\text { coefficient }\end{array}$ & Slip ratio: $20 \%$, water film thickness: $0.5 \mathrm{~mm}$, meas & ASTM 1551 tire $(2$ \\
\hline ROAR NL & $\begin{array}{r}\text { Longit } \\
\mathrm{C}\end{array}$ & arement & ASTM 1551 tire $(2$ \\
\hline SCRIM & $\begin{array}{l}\text { Sideway friction } \\
\text { coefficient }\end{array}$ & $\begin{array}{l}\text { Slip angle: } 20^{\circ} \text {, water film thickness: } \\
\text { speed: } 50 \mathrm{~km} / \mathrm{h} \text {; it measures }\end{array}$ & $\begin{array}{l}\text { Avon SCRIM smooth profile tire } \\
(350 \mathrm{kPa}) \text {, wheel load: } 1960 \mathrm{~N}\end{array}$ \\
\hline SKM & tion & $\begin{array}{l}\text { Slip angle: } 20^{\circ} \text {, water film thickness: } 0.5 \mathrm{~mm} \text {, measurement } \\
\text { speed: } 50 \mathrm{~km} / \mathrm{h}\end{array}$ & $\begin{array}{c}\text { Smooth profile tire, wheel load: } 1960 \\
\text { N }\end{array}$ \\
\hline SRM & $\begin{array}{l}\text { Longitudinal friction } \\
\text { coefficient }\end{array}$ & $\begin{array}{c}\text { Slip ratio: } 15 \% \text { or } 100 \% \text {, water film thickness: } 0.5 \mathrm{~mm} \text {, } \\
\text { measurement speed: } 40,60,80 \mathrm{~km} / \mathrm{h}\end{array}$ & $\begin{array}{l}\text { AIPCR tire with longitudinal tread } \\
\text { 165R15, wheel load: } 3500 \mathrm{~N}\end{array}$ \\
\hline TRT & $\begin{array}{l}\text { Longitudinal friction } \\
\text { coefficient }\end{array}$ & $\begin{array}{l}\text { Slip ratio: } 25 \% \text {, water film thickness: } 0.5 \mathrm{~mm} \text {, measurement } \\
\text { speed: } 65 \mathrm{~km} / \mathrm{h}\end{array}$ & $\begin{array}{l}\text { Smooth profile ASTM tire, wheel load: } \\
\qquad 1000 \mathrm{~N}\end{array}$ \\
\hline IMAG & $\begin{array}{l}\text { Longitudinal friction } \\
\text { coefficient }\end{array}$ & $\begin{array}{c}\text { Slip ratio: } 100 \% \text {, water film thickness: } 1.0 \mathrm{~mm} \text {, measurement } \\
\text { speed: } 40-140 \mathrm{~km} / \mathrm{h}\end{array}$ & $\begin{array}{l}\text { PIARC smooth profile tire, wheel load: } \\
\qquad 1500 \mathrm{~N}\end{array}$ \\
\hline
\end{tabular}

considered to be within highway agency's control are microtexture, macrotexture, pavement material properties, tire tread design, and slip speed of the tire.

3.1. Pavement Surface Associated Factors. Most of the surface characteristics are believed to be within the control of highway authorities excluding surface ageing. In this section, an overview of surface texture, surface type, aggregate properties, and surface ageing is given, and their influence on skid resistance is presented in the subsequent sections. Road surface textures are a deviation from a planer and smooth surface which affects tirepavement interaction. Pavement surface texture is characterized by asperities present in a pavement surface. The two levels of texture that predominantly affect friction are microtexture and macrotexture [27]. Previous studies [28, 29] suggested that a deeper pavement texture is necessary to have sufficient wet skid resistance particularly for a vehicle travelling at higher speeds. The most important factor for skid resistance is pavement macrotexture. In France, it is determined that accident risk rapidly increases for the road surface having a mean texture depth less than $0.5 \mathrm{~mm}$ [30]. Correlation between mean profile depth (MPD) measured by laser scanning and skid resistance measured by locked wheel skid tester as proposed by Meegoda and Gao [31] showed a positive trend for an MPD value less than $0.80 \mathrm{~mm}$, and then skid resistance was found to start decreasing till an MPD value of $1.1 \mathrm{~mm}$. Again, it was found to be almost constant with MPD values of 1.1 to $1.4 \mathrm{~mm}$. A study done by Larson [32] also found that the risk of wet crashes increases greatly for surfaces with an estimated texture depth of less than $0.40 \mathrm{~mm}$.

3.1.1. Effect of Pavement Microtexture. Microtexture present in the pavement surface is the degree of roughness imparted by individual aggregate particles. It is also defined as deviations of pavement surface with a characteristic dimension of wavelength and amplitude less than $0.55 \mathrm{~mm}$ as per ASTM 867. It refers to the small-scale texture of the aggregate surface, which controls the contact between the tire rubber and pavement surface. Microtexture is a function of aggregate particle mineralogy and petrology, the aggregate source, and is affected by environmental effects and action of traffic $[17,33]$. It is mainly responsible for pavement friction at low speed. In warm regions with low viscosity bitumen, the binder gets transformed into a molten state at higher temperature and starts flowing and filling micropores available in the surface, reducing the microtexture of the pavement. Contaminants such as dust, debris, salt, and sand also act as filling agents and reduce microtexture. The polishing effect of traffic on the aggregate of the pavement surface might result in lower microtexture. The rougher the microtexture, the higher the pavement friction and hence the skid resistance [34]. Chen [35] suggested that the surface of the coarse aggregate tended to have a smooth microtexture due to reducing the actual contact area of road surface, and skid resistance ability of surface would also decrease. Due to the fact that polishing of aggregate in the pavement is a long-term process, microtexture is more important for long-term skid resistance of aggregates [36]. The microtexture seems to increase after the initial exposure of the aggregates to traffic, as traffic polishing wears away the overlying film of asphalt binder that covers the aggregate asperities [23]. Skid resistance also presents the same increasing trend. After this increasing phase, skid resistance tends to decrease over the remaining pavement life as these exposed aggregates become increasingly more polished by the cumulative traffic passing $[37,38]$. The microtexture of aggregates also helps cut through the water film between the aggregates and tire rubber, thus playing an important role in wet skid resistance [39]. Horne [40] also stated that pavement with a good microtexture can delay hydroplaning. 
TABLE 3: Overview of pavement surface texture measurement methods.

\begin{tabular}{|c|c|c|c|}
\hline Method & Measuring principle & Advantage & Disadvantage \\
\hline $\begin{array}{l}\text { Computed } \\
\text { tomography }\end{array}$ & $\begin{array}{l}\text { Based on attenuation of X-rays. A 3D } \\
\text { voxel is reconstructed and a grey } \\
\text { value is attributed to each voxel } \\
\text { depending on X-ray absorption of } \\
\text { surface and path followed by X-ray. }\end{array}$ & $\begin{array}{c}\text { Nondestructive testing. Determination } \\
\text { of inner and outer geometry, volume } \\
\text { data of high density, short scanning } \\
\text { time. Higher accuracy if reconstructed } \\
\text { correctly. }\end{array}$ & $\begin{array}{l}\text { Complex and numerous parameters } \\
\text { influencing measurement, with results } \\
\text { being not traceable. No accepted test } \\
\text { procedure. Highly sophisticated, } \\
\text { requiring a skilled operator. }\end{array}$ \\
\hline Microscopy & $\begin{array}{l}\text { Based on an image captured by } \\
\text { camera or microscope and analysed } \\
\text { using proprietary software for } 3 \mathrm{D} \\
\text { modelling of capture surface. }\end{array}$ & $\begin{array}{l}\text { Inexpensive. Ability to visualize } \\
\text { surface texture in 3D. Covering micro-, } \\
\text { macro- \& megatexture scale. } \\
\text { Correlating well with MTD from sand } \\
\text { patch test. }\end{array}$ & $\begin{array}{l}\text { Accuracy depends on user-adopted } \\
\text { imaging setup, lens optics \& } \\
\text { eliminating the effect of camera shake. } \\
\text { Requiring skill \& software for analysis } \\
\text { of 3D models. }\end{array}$ \\
\hline Laser scanning & $\begin{array}{c}\text { Recording intensity of reflected laser } \\
\text { light from the target surface \& lens } \\
\text { height for each point under } \\
\text { observation. }\end{array}$ & $\begin{array}{l}\text { No surface damage. A simultaneous } \\
\text { and quick observation of surface image } \\
\text { and the height profile. Continuous data } \\
\text { collection at high speed. Ability to } \\
\text { calculate MPD \& RMS of profile } \\
\text { height. }\end{array}$ & $\begin{array}{l}\text { Limited measurement target size. } \\
\text { Expensive, requiring skilled operators } \\
\text { for data collection \& processing. } \\
\text { Inability to determine the internal } \\
\text { structure of the surface mix. }\end{array}$ \\
\hline $\begin{array}{l}\text { Sand patch } \\
\text { method }\end{array}$ & $\begin{array}{l}\text { Patch area is calculated by pouring } \\
\text { fixed volume of sand or glass spheres } \\
\text { over the surface. Mean texture depth } \\
\text { (MTD) is obtained by dividing the } \\
\text { volume of sand or glass sphere by } \\
\text { calculated patch area. }\end{array}$ & $\begin{array}{l}\text { It is simple to use and is the least } \\
\text { expensive among all. It is useful in } \\
\text { every type of pavement surface } \\
\text { measurement. It directly measures } \\
\text { mean texture depth. Surface profiling } \\
\text { can be constructed in 3D. }\end{array}$ & $\begin{array}{l}\text { It cannot accurately predict the texture } \\
\text { of a very rough or porous surface. It is } \\
\text { vulnerable to operator inconsistencies. } \\
\text { Repeated measurements at regular } \\
\text { intervals are required. It is a slow } \\
\text { method; traffic management is } \\
\text { required to protect the operator. }\end{array}$ \\
\hline Outflow meter & $\begin{array}{l}\text { It is based on a known volume of } \\
\text { water, under a standard pressure } \\
\text { head, which is then allowed to } \\
\text { disperse through the gaps between a } \\
\text { circular rubber ring and the road } \\
\text { surface. It relates to the drainage } \\
\text { capability of the pavement through its } \\
\text { surface and subsurface voids. }\end{array}$ & $\begin{array}{c}\text { It is useful for an open-graded porous } \\
\text { asphalt surface. It indicates } \\
\text { hydroplaning potential under wet } \\
\text { conditions. It is simple to execute and } \\
\text { needs inexpensive equipment. It } \\
\text { measures the relative drainage ability } \\
\text { of the pavement surface and detects } \\
\text { surface wear. }\end{array}$ & $\begin{array}{l}\text { It is appropriate only for surfaces with } \\
\text { low texture depth. Reproducibility is } \\
\text { poor. It cannot measure outflow time } \\
\text { less than } 1 \text { sec. It does not measure the } \\
\text { texture depth directly. It is a slow } \\
\text { method and requires lane closure to } \\
\text { perform the test. }\end{array}$ \\
\hline $\begin{array}{l}\text { Circular texture } \\
\text { meter }\end{array}$ & $\begin{array}{c}\text { It uses a laser to measure the profile of } \\
\text { a circle and is divided into eight } \\
\text { segments. The average MPD is } \\
\text { determined for each segment of the } \\
\text { circle. }\end{array}$ & $\begin{array}{l}\text { It is a small (approx. } 13 \mathrm{~kg} \text { ) and } \\
\text { portable instrument, with short } \\
\text { measurement time (approx. } 45 \mathrm{sec} \text { ). } \\
\text { Four directions of data can be obtained } \\
\text { during only one measurement. }\end{array}$ & $\begin{array}{l}\text { It does not record the } 3 \mathrm{D} \text { surface } \\
\text { profile. It is not practical in measuring } \\
\text { the macrotexture of large pavement } \\
\text { segments. It underestimates the actual } \\
\text { texture. }\end{array}$ \\
\hline $\begin{array}{l}\text { Light detection } \\
\text { and ranging } \\
\text { (LiDAR) }\end{array}$ & $\begin{array}{l}\text { Parameters related to texture and } \\
\text { material information are detected } \\
\text { and calculated by LiDAR system. }\end{array}$ & $\begin{array}{c}\text { It can be equipped on vehicles for rapid } \\
\text { and economical estimation of } \\
\text { pavement friction level. }\end{array}$ & $\begin{array}{l}\text { The test accuracy is affected by road } \\
\text { markings, natural light \& weather } \\
\text { conditions. More data is needed to } \\
\text { improve the accuracy of the estimation } \\
\text { of the friction. }\end{array}$ \\
\hline
\end{tabular}

TABLE 4: Factors affecting available skid resistance at tire-pavement interface.

\begin{tabular}{lccc}
\hline Surface characteristics & Vehicle parameters & Tire properties & Environmental conditions \\
\hline Microtexture & Vehicle speed & Tire footprint & Temperature \\
Macrotexture & Slip ratio & Tread pattern & Rain Intensity \\
Surface type & Braking action & Inflation pressure & Contamination \\
Aggregate properties & Tire inclination & Loading condition & \\
Surface ageing & & & \\
\hline
\end{tabular}

3.1.2. Effect of Pavement Macrotexture. Macrotexture present in the pavement surface is the degree of roughness imparted by the deviation among aggregate particles. As per ASTM 867, the macrotexture is a deviation of pavement surface with characteristic dimension from $0.5 \mathrm{~mm}$ up to a value that no longer affects tire-pavement interaction. It is mainly responsible for reducing the potential for separating tire and pavement surface due to hydroplaning and for inducing friction due to hysteresis for vehicles travelling at high speed [4]. The macrotexture of the pavement can be estimated by simulating the percentage of contact points within the area of tire footprints on the pavement surface [41].

Aggregate gradation, compaction levels achieved, and binder properties mainly influence macrotexture [33]. Previous studies by Smiley and Horne [28] and Chen et al. 
[29] suggested that a deeper pavement texture is necessary to have sufficient wet skid resistance particularly for a vehicle travelling at higher speeds. Bloem [42] showed that an average texture depth of about $0.5 \mathrm{~mm}$ is required as a minimum to ensure the desired depletion of water under the tire. Repetitive movement of traffic on road surface causes polishing of surface aggregates resulting in smoothing and rounding of exposed aggregates. Polishing of surface aggregates is the reduction in the macrotexture of pavement and is caused due to wearing action of tires on aggregates at the microscopic level. Liu et al. [43] investigated the effect of surface macrotexture on skid resistance measurements using the British pendulum test. The test results showed that the macrotexture of a test surface had a significant effect on lowspeed frictional resistance. The surface macrotexture parameters of aggregate size and gap width were found to have a significant effect on the magnitude of surface frictional resistance. Skid resistance at pavement surface decreases as polishing of surface aggregates increases. It has been observed that a porous surface offers more resistance to vehicular movement as compared to a dense and smooth surface. Studies reveal that porous asphalt surfaces possess more macrotexture than ultrathin surfaces which in turn offer more macrotexture and hence more hysteretic friction than stone mastic asphalt [15]. Both macrotexture and skid resistance are found to increase after the initial exposure of the aggregates to traffic as wearing of overlying binder film takes place [23]. The initially achieved macrotexture level of the asphalt mixture can also influence the long-term polishing behaviour of an asphalt road surface $[36,44]$. Figure 3 represents various texture ranges as established by PIARC [45].

3.1.3. Effect of Pavement Surface Type. Skid resistance is significantly affected by the variation in asphalt mix, as a mix provides scope for the variation in aggregate gradation, with a wide range of its mineralogy, shape, size, and angularity in aggregates and binder content of the mix. It has been observed that a porous surface offers more resistance to vehicular movement as compared to a dense and smooth surface. Studies reveal that porous asphalt surfaces possess more macrotexture than ultrathin surfaces which in turn offer more macrotexture and hence more hysteretic friction than stone mastic asphalt [46]. When comparing open-graded friction course (OGFC), stone mastic asphalt (SMA), and asphalt concrete (AC), OGFC pavement showed the highest adhesion property followed by SMA pavement and then the AC pavement. This indicates that the OGFC designed with open gradation has better skid resistance than other gradation pavement [47]. Dense-graded HMA shows lower macrotexture depths (typically $0.4-0.6 \mathrm{~mm}$ for fine-graded and $0.6-1.2 \mathrm{~mm}$ for coarse-graded) than gapgraded and open-graded mixes [48]. A study on the effect of binder content in the mix on skid resistance presented by Asi [49] shows that increasing the asphalt content beyond optimum value decreases the skid resistance of the mixes. Further, he concluded that the mix designed as per Superpave mix design procedure has better skid resistance than those designed using Marshall mix design procedure.

\subsubsection{Effect of Geological Properties of Aggregate.} Aggregate is the main constituent of the asphalt mix and controls the volumetric properties of the mix significantly. Depending upon the geological formation, mineralogy, shape, size, and angularity of aggregate, it offers variable mean profile depth and mean texture depth in the constitutive mix which in turn provides a wide range of surfaces with different roughness characteristics. Researchers have tried to identify the effect of geological properties of aggregates on the skid resistance of the surface and have studied aggregate mineralogy and geometry, their shape, and their size in detail. Hard, polish-resistant coarse aggregates are essential to avoid reducing skid resistance of asphalt surface [42]. The role of fine aggregates becomes significant only when used in relatively large quantities [50]. Magnoni et al. [51] evaluated the effect of aggregate mineralogy and geometry on asphalt mixture friction and made some important conclusions based on aggregate mineralogy and geometry, its shape, and its volumetric characteristics as follows:

Mineralogy and Geometry. Fine aggregate content (normally $0.063-2 \mathrm{~mm}$ ) appears to be the most significant parameter to influence microtexture and British pendulum number (BPN). With the increase in fine aggregate content and basalt content, BPN value was found to increase. On the contrary, mean texture depth decreases with an increase in fine aggregate content and basalt content.

Shape. The decrease of nonpolyhedral particles into the mixture appears to be detrimental in terms of microtexture but raises the mean texture depth value.

Rocks containing igneous and metamorphic constituents are less susceptible to polishing than sedimentary rock and can improve skid resistance characteristics of pavement [52]. Liang and Chyi [53] found that as the calcite and dolomite content increases, the polish susceptibility of aggregates decreases.

3.1.5. Effect of Ageing of the Surface. All new road surfaces have high texture and skid resistance. Surface texture, however, reduces over time due to the abrasive effect of traffic. Traffic has a cumulative effect on pavement, and it wears the pavement surface and polishes the aggregates [54]. The polishing of aggregates is due to horizontal forces applied by moving vehicles. Under these forces, protruding aggregates are worn off and polished, thus reducing surface texture [41, 55-57]. The polishing of aggregates makes the surface more slippery due to a reduction in skid resistance. Commercial vehicles contribute to most of the aggregate polishing [58]. Aggregates used in highway construction have to be resistant to abrasion and crushing to provide adequate skid resistance even after the long-term ageing of pavement [59]. During the early life of road surface, i.e., just after its construction, skid resistance increases due to scouring of the initial film of binder located on pavement surface [23]. As the binder removal phase initiates with the passes of traffic, the microtexture of aggregates gradually 


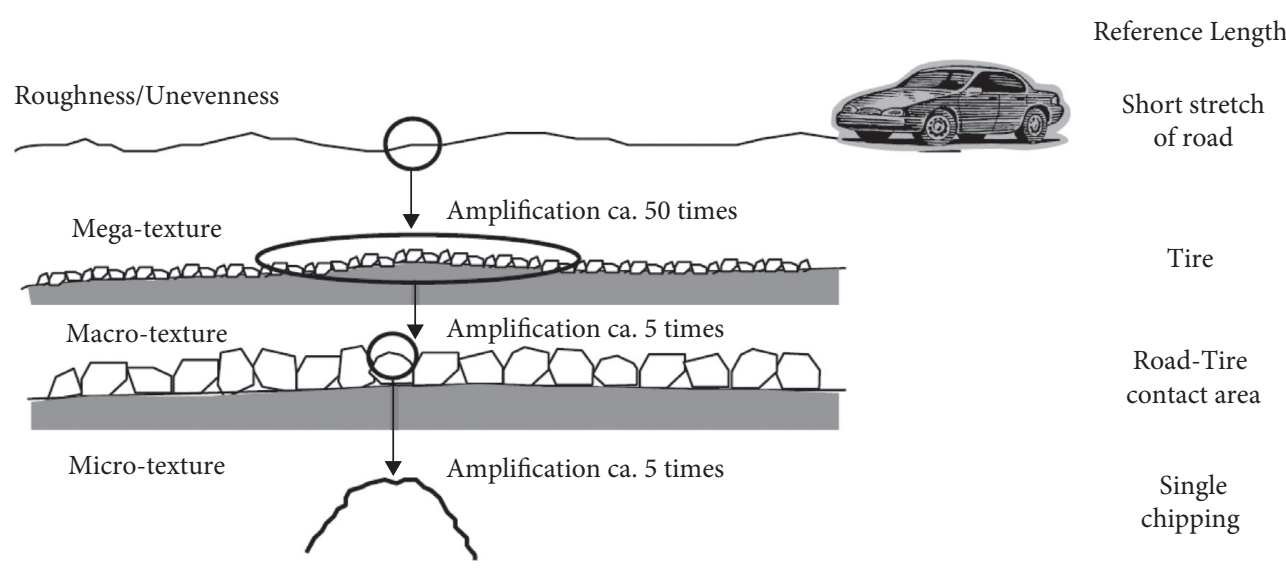

FIgURE 3: Illustration of the various texture ranges that exist for a given pavement surface [45].

starts exposing, and then actual polishing, differential wear, and weathering of aggregates begin with cumulative passes of the vehicle which in turn converts angular aggregates into rounded aggregates. Figure 4 shows the variation of pavement skid resistance versus pavement age.

3.2. Vehicle Operation Associated Factors. In this section, an overview of vehicle-related parameters like vehicle speed, tire inclination, braking action, and slip ratio is provided, and their influence on skid resistance is presented in the subsequent subsections. Slip ratio is the most critical factor among all vehicle operation associated factors which control skid resistance at tire-pavement interface significantly. Other factors are believed to be under the control of highway engineers and are relatively less critical in the context of their variation with skidding at the surface.

3.2.1. Effect of Vehicle Speed. Vehicular speed proves to be more critical in wet surface conditions, as with increasing speed, tire tread gets lesser time for channelling out more and more water at tire-pavement interface. The stopping distance of the vehicle is another aspect that increases with increasing speed which in turn poses a serious concern for road users. Skid resistance falls rapidly as the speed of the vehicle increases, and it is minimal around a speed of $100 \mathrm{~km} / \mathrm{hr}$ [61]. During wet weather conditions, vehicles travelling at high speed are considered at a higher risk of skidding [62]. It is because there is not sufficient time for the accumulated water to escape from the tire-surface contact zone.

3.2.2. Effect of Slip Ratio. Slip ratio is the difference between theoretically calculated forward speed based on angular speed of the rim and rolling radius, and actual speed of the vehicle. Researchers use this "slip ratio" term to differentiate tire velocity and vehicle velocity. When the tire is rolling freely, the slip ratio is 0 . On the other hand, when the tire is locked, the slip ratio is 1 . The locked wheel suffers from localized wear due to no rolling. Classical relation between friction and slip ratio shows that decrease in friction is continuous over a threshold slip ratio. Researchers have tried to identify the relation of tire slip ratio with pavement friction and connected slip ratio of the tire with sliding friction at surface. Lower friction values are unsafe for safe driving conditions and are observed at nearly locked wheel conditions. The coefficient of friction between a tire and the pavement changes with varying slips as shown in Figure 5. It increases rapidly when increasing the slip to a peak value that usually occurs between 10 and 20 percent slip ratio. The friction then decreases to a value known as the coefficient of sliding friction, which occurs at 100 percent slip ratio [27]. A tire with $86 \%$ slip ratio provides lower hysteretic friction than a one with $20 \%$ slip ratio [15].

3.2.3. Effect of Tire Inclination. Effect of tire inclination is observed at circular curves and turnarounds or intersections where pressure on one side of vehicle increases and effect of asymmetric load, speed, and vehicle manoeuvring is observed altogether. Tire inclination increases shear resistance at the interface. Maximum shear stress increases with an increase in tire inclination angle from $0^{\circ}$ to $10^{\circ}$ [63]. This suggests that a section of pavement with a higher volume of turning traffic (at intersections) may be more susceptible to shear and surface rutting failure.

3.3. Tire Associated Factors. The tire is one of two interacting bodies that come in contact at the tire-pavement interface. The tire is a complex 3-dimensional structure that facilitates loading at the pavement surface with the help of tire inflation pressure. It becomes essential to know peculiar characteristics of the tire tread pattern and inflation pressure in the context of skid resistance control at the tirepavement interface. The tire tread pattern is one the most critical factors affecting skid resistance at the interface significantly, as tread depth controls the drainage capacity of the tire and contact area at the interface. The following section discusses the effect of tread pattern tire inflation and traffic load on the skid resistance of the pavement surface. 


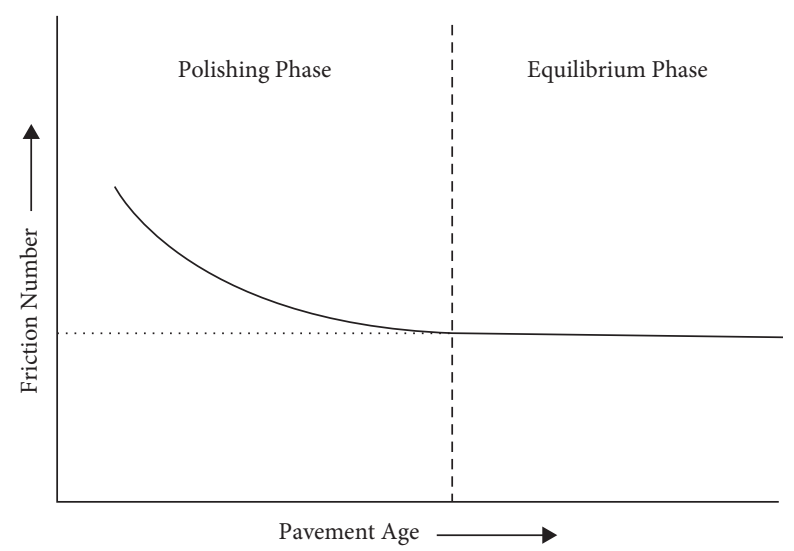

Figure 4: Decrease of pavement skid resistance due to the polishing of traffic [60].

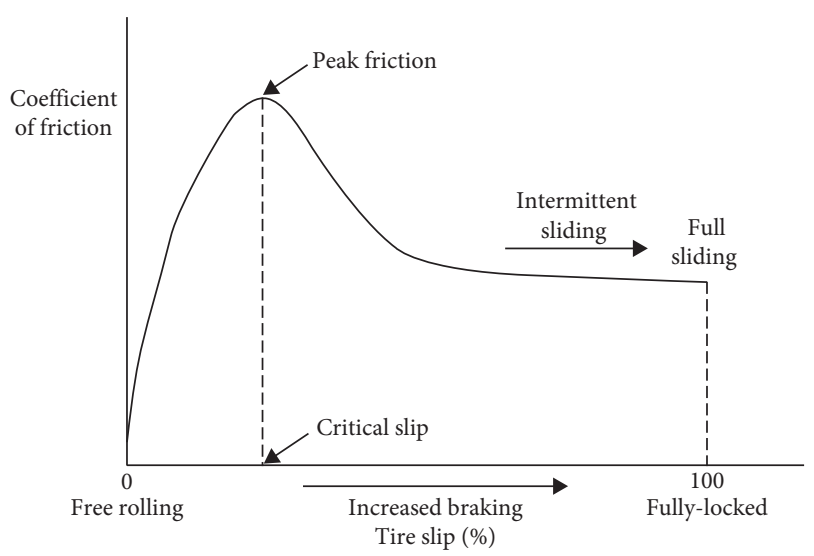

Figure 5: Pavement longitudinal friction versus slip [27].

3.3.1. Effect of Tire Tread Pattern. Tread is the hard rubber on the circumference of a tire that comes directly in contact with the road surface. It affects ride and handling, rolling resistance, noise, and vibration aspects of tire-pavement interaction. Deep treaded tires are generally considered an important measure for channelling away accumulated water at tire-pavement contact zone [64-67]. If the depth of treads decreases as in the case of worn-out tires, the capacity to drain the water through the treads also decreases, which is a serious concern to the safety of driving. Therefore, a minimum legal depth for the tread has been specified in many countries (e.g., a minimum tread depth of $1.6 \mathrm{~mm}$ has been specified in the UK, the USA, and Canada, [68]). Deep treaded tires provide higher grip and maintain necessary friction between tire and pavement. The depth of tread is particularly important for vehicles driving over thick films of water at high speeds. In a study by Henry and Saito [69], a decrease in wet friction of 45 to 70 percent has been reported for fully worn tires, compared to new ones.

3.3.2. Effect of Tire Inflation Pressure. Inflation pressure and frictional characteristics of pavement surface are directly related to tire stiffness; hence, there exists a direct correlation between inflation pressure and skid resistance. The study of tire inflation pressure in highway engineering has always been a topic of great interest as it determines safety as well as economy. Inflation pressure of vehicular tire affects fuel consumption, tire tread wear, rolling resistance, tire footprint area, and skid resistance. As the inflation pressure reduces, it results in more contact of the tire with the pavement. This increases adhesion and hysteresis between the road surface and tire. This in turn contributes to increasing skid resistance experienced by vehicles in motion. Researchers have tried to examine the effect of varying inflation pressure on skid characteristics of the pavement surface and found that when tire pressure is reduced by $28.57 \%$, rolling resistance force was increased by $48.52 \%$. When tire pressure was increased by $28.57 \%$, rolling resistance was found to reduce by $13.46 \%$ [70]. In another study, it was shown that lower tire pressure will be reflected in higher rolling resistance [71].

3.3.3. Effect of Traffic Load. Traffic load becomes a key parameter in controlling skid resistance at pavement surface when considered in long terms as it gets multiplied and appears in cumulative form. Cumulative traffic load is a serious concern to pavement safety as it starts polishing aggregates in the mix. Polishing of aggregates makes the surface smoother and consecutively skid resistance decreases. Few studies on the impact of traffic load on skid resistance have been reviewed here for the sake of understanding the general trend of variation. As traffic load keeps on increasing, skid resistance decreases in the long term despite any interim increase [30]. Plati and Pomoni [72] investigated the long-term effect of traffic volume on skid resistance and macrotexture and observed that the traffic effect is not a constant factor during pavement service life. In one zone, it was observed that mean profile depth (MPD) and skid resistance exhibited a slow decrease with fluctuations during their evolution period, and in another zone of the test, which starts after a certain volume of cumulative traffic, mean profile depth presented an inverse trend with skid resistance: as MPD increases, skid resistance decreases. It is also noted that the rate of heavy traffic and road geometric characteristics are more critical for skid resistance and macrotexture evolution than the total traffic flow. 
TABLE 5: Factors affecting skid resistance and their history in modelling frictional characteristics.

Author
Meegoda and Gao [31]
Kogbara et al. [92]
Kouchaki et al. [19]
Chen et al. [29]
Peng et al. [93]
Zhou et al. [94]
Kangkhajitre and Kanitpong
Mah]

Magnoni et al. [51]

Asi [49]

Kane et al. [98]

Zhang et al. [99]

Oh et al. [100]

Plati and Pomoni [72]

Bazlamit and Reza [77];

Fuentes [71]; Baran [75]

Reza and Bazlamit [101]

Hosking [73]; McDonald et al. [74]

Anupam et al. [46]
Surface roughness

Aggregate type and mix design

Aggregate properties

Aggregate properties

Aggregate mineralogy and geometry

Asphalt mix

Binder ageing

Pavement type

Traffic \& environment

Traffic volume

Air temperature

Ambient temperature

Air temperature

Temperature, texture \& slip ratio

Comments

The correlation between skid resistance and mean profile depth (MPD) was found positive for MPD values less than 0.8; then, the trend shows a negative correlation with increasing MPD until it is $1.1 \mathrm{~mm}$, after which skid number remains constant with increasing MPD values.

Lane with higher grip numbers generally had higher individual texture parameters.

The study performed a series of statistical analyses of field-measured friction and texture data. The results indicated a strong positive correlation between friction and surface texture.

Tire-pavement friction was measured using a dynamic friction tester, and it was found to increase initially and then start decreasing till significant polishing of the surface.

The binary search back-calculation method is used to derive the rubber pavement interface friction to fit simulated skid resistance with in situ skid resistance.

The experimental result proved that friction coefficient decreases with decreasing surface roughness for a frequency of $2 \mathrm{~Hz}$. For the frequency of 4 and $6 \mathrm{~Hz}$, the friction coefficient decreases at first and then increases with decreasing surface roughness.

If a mix possesses adequate volumetric properties, pavement texturing by milling or grooving appears to hold considerable promise as a method of increasing skid resistance of low friction bituminous pavement.

Friction value was found to decrease with an increase in aggregate polishing cycles due to a decrease in surface texture.

Polishing stone value, angularity, and texture of aggregate significantly affect the frictional characteristics of the asphalt mix.

An increase of up to $10 \%$ of BPN was observed according to fine aggregate content and basalt content. Compaction characteristics produce a general increase in British pendulum number.

With the addition of steel slag in asphalt mix and using SMA mix, the skid resistance of the surface can be improved. Increasing the asphalt content above optimum value decreases skid resistance.

The friction coefficient was found to increase sharply with initial binder ageing, and then it became almost constant for long-term ageing of bitumen.

The use of porous pavement resulted in a lower fluid uplift force, better tire-pavement contact, higher traction, and less tire deformation, all of which are essential to having a higher skid number.

Average daily traffic and age of pavement have a negative effect on skid resistance. Resurfacing with open-graded asphalt concrete significantly decreases the number of wet collisions.

Traffic effect is not a constant factor during pavement service life. The study of different zones indicated the different effects of the cumulative traffic volume on skid resistance. Skid resistance in one zone exhibited a slow decrease attributed to short-term variation effect, while in another zone, which starts after a certain cumulative volume, MPD \& skid resistance presented an inverse trend.

Skid resistance decreases with increased temperature. An approximately linear result was found between skid resistance and temperature based on a variety of asphalt pavements.

For a polished asphalt surface, skid resistance decreases with increased temperature. An approximately linear relationship between skid resistance and temperature was found.

The measured friction coefficient tends to decrease with increasing air temperature.

A higher pavement temperature, air temperature, and contained air temperature always result in lower hysteretic friction; however, a lower tire slip ratio and a pavement with higher macrotexture would result in higher friction. 
TABle 5: Continued.

\begin{tabular}{|c|c|c|}
\hline Author & Parameters & Comments \\
\hline Srirangam et al. [15] & $\begin{array}{c}\text { Tire temperature, surface } \\
\text { type }\end{array}$ & $\begin{array}{l}\text { Hysteretic friction decreases with an increase in tire temperature. The } \% \\
\text { decrease in hysteretic friction from a porous asphalt surface to an ultrathin } \\
\text { surface and a stone mastic asphalt surface was observed to be } 11 \% \text { and } 22 \% \text {, } \\
\text { respectively. }\end{array}$ \\
\hline Leu and Henry [102] & Vehicle speed & $\begin{array}{l}\text { They conducted test at a number of BPN values and test speeds and found } \\
\text { that skid resistance decreases with the increase in speed. }\end{array}$ \\
\hline Sun et al. [103] & Speed and temperature & $\begin{array}{l}\text { The friction coefficient between tire and road surface becomes smaller with } \\
\text { an increase in velocity. Relation between temperature and friction has a } \\
\text { peak value which is related to isoprene molecular shape. }\end{array}$ \\
\hline Tang et al. [104] & $\begin{array}{l}\text { Ambient temperature, speed, } \\
\text { pressure \& load }\end{array}$ & $\begin{array}{l}\text { They developed a thermomechanical tire-pavement interaction model } \\
\text { using FEM. It was shown that a rise in temperature causes a significant } \\
\text { reduction in skid resistance. A similar trend with speed and inflation } \\
\text { pressure was noted; however, increase in skid resistance was observed with } \\
\text { an increase in load. }\end{array}$ \\
\hline Srirangam et al. [105] & $\begin{array}{l}\text { Sliding speed, pressure \& } \\
\text { macrotexture }\end{array}$ & $\begin{array}{l}\text { Rubber friction is found to inversely vary with the sliding speed and } \\
\text { positively vary with pressure for all the pavement morphological and } \\
\text { stiffness conditions. Highly porous pavement surface results in large } \\
\text { rubber friction. }\end{array}$ \\
\hline Zheng et al. [47] & $\begin{array}{c}\text { Tire inflation pressure, speed, } \\
\text { pavement type }\end{array}$ & $\begin{array}{l}\text { The tire friction coefficient increases with an increase in inflation pressure } \\
\text { and the overall trend presents a parabolic curve. The friction coefficient } \\
\text { decreases gradually with an increase in speed. The open-graded friction } \\
\text { course pavement has the highest adhesion property followed by SMA and } \\
\text { then asphalt concrete. }\end{array}$ \\
\hline Shakely et al. [88] & Contaminants & $\begin{array}{l}\text { A straight-line relationship between skid resistance and dust loading was } \\
\text { observed up to a point at which it appears that the further increase in dust } \\
\text { loading has no effect on reducing skid number values. Particles smaller } \\
\text { than } 7 \text { micrometres have no significant effect on skid resistance values. }\end{array}$ \\
\hline Cao et al. [106] & Contaminants & $\begin{array}{l}\text { Effect of contaminants increases with the increase in area covered by } \\
\text { contaminants in the contact area. The largest effect on skid resistance } \\
\text { occurred when all contact area was covered by contaminants. }\end{array}$ \\
\hline Lubis et al. [90] & Contaminants & $\begin{array}{l}\text { Skid resistance of the pavement surface decreased after the contaminants } \\
\text { were covered in water, sand, salt, and lubricant by } 20.1 \%, 22.8 \%, 37.1 \% \text {, and } \\
\qquad 50.5 \% \text {, respectively. }\end{array}$ \\
\hline Maycock [64] & Tire tread & $\begin{array}{l}\text { On smooth surfaces, a worthwhile increase in wet road adhesion at high } \\
\text { speeds is possible by suitable design of tire tread pattern. Coarse texture } \\
\text { surfaces have better inherent drainage properties \& enable water to be } \\
\text { more readily removed between tire and road surface. }\end{array}$ \\
\hline Changyong [107] & $\begin{array}{l}\text { Tread depth, load, water } \\
\text { depth }\end{array}$ & $\begin{array}{l}\text { Simulation results indicated a decrease in skid resistance with reducing tire } \\
\text { tread depth and a similar trend with wheel load. Skid resistance generally } \\
\text { decreases with increasing water film thickness and vehicle speed. }\end{array}$ \\
\hline Tang et al. [78] & Rain intensity & $\begin{array}{l}\text { It was indicated that the risk of safe driving significantly increases for a } \\
\text { vehicle travelling at high speed under high rainfall intensities. Pavement } \\
\text { with higher porosity and passenger car/truck tire with proper tread pattern } \\
\text { are necessary for the increment of wet skid resistance. }\end{array}$ \\
\hline
\end{tabular}

3.4. Environment Associated Factors. All of the parameters associated with the environment are completely out of the control of pavement engineers and highway authorities; however, some remedial measures can be taken to counter their bad impact on pavement safety. Temperature (whether it is pavement temperature, ambient temperature, or contained air temperature of the tire), surface wetting due to rainwater exposure, and surface contaminants are believed to be critical parameters affecting skid resistance and pavement safety at tire-pavement interface and are discussed in subsequent sections in brief.
3.4.1. Effect of Temperature. Pavement temperature (temperature of pavement surface), ambient temperature (air temperature), and contained air temperature (temperature of the air within tire's air chamber) play a vital role in deciding skid resistance at tire-pavement interface as these temperature conditions change bitumen rheology (flow tendency) and tire rubber behaviour. During the last fifteen years, some studies tried to separately establish the relation between pavement temperature, ambient temperature, and contained air temperature and skid resistance. Here, we present few of the outcomes of these studies. According to 
several studies [71, 73-75], the measured coefficient of friction tends to decrease with increasing air temperature. The mechanism involved in the variation due to temperature changes is attributed to hysteresis of the tire rubber [76]. Hysteresis is the energy lost upon elastic recovery in the form of heat when a tire rubber is compressed as it slides over the pavement. Effect of ambient temperature on skid resistance was studied by Bazlamit and Reza [77] who observed a decrease in skid resistance as temperature increases, following a linear relationship. Pavement-tire friction generally decreases with increasing tire temperature, though this is difficult to quantify [17]. The skid resistance of a wet road surface is greater in winter than in summer as rubber resilience increases and hysteresis loss decreases with the increase in temperature. Both effects combine to reduce the skid resistance value as temperature increases [55]. Past studies show that a higher pavement temperature, ambient temperature, and contained air temperature will result in lower hysteretic friction for a given tire slip ratio (ratio of theoretical forward speed and actual speed of the vehicle) and pavement, highlighting the importance of keeping the macrotexture of the pavement rough in warm locations [15]. This can be justified by the fact that the temperature-dependent viscoelastic property of rubber in the tire has a great influence on hysteretic friction. It necessitates the proper consideration of temperature effect on skid resistance, ignoring which can lead to severe corrective maintenance to pavement structure.

3.4.2. Effect of Rain Intensity. Wet skid resistance varies under different rainfall conditions and is influenced by various factors such as surface porosity, geometric design of pavement, and tire operating conditions [78]. During wet weather driving conditions, the water on the pavement acts as a lubricant which reduces the contact area at the tirepavement interface $[79,80]$. As a consequence, skid resistance decreases, and the chances of skid-related traffic accidents increase [81]. The adverse effect of the presence of a water film on skid resistance has been highlighted in many research studies $[82,83]$. The study of surface wetting effect on skid resistance is very complex and needs mathematical modelling of hydroplaning. With the advancement in finite element formulations [84], the study of skid resistance variation with rain intensity has gained significant attraction, and various researchers have identified few key relations, some of which are discussed here briefly. The coefficient of friction of a vehicle tire sliding over a wet pavement surface decreases exponentially as water film thickness (WFT) increases. The rate at which the coefficient of friction decreases generally becomes smaller as WFT increases [17]. Test results from an FHWA-sponsored study by Harwood et al. [85] indicated that as little as $0.05 \mathrm{~mm}$ of water on the pavement surface can reduce the coefficient of friction by 20 to 30 percent of the dry coefficient of friction. Loss of direct pavement-tire contact can occur at speeds as low as 64 to $72 \mathrm{~km} / \mathrm{hr}$ on puddles about $25 \mathrm{~mm}$ deep and $9 \mathrm{~m}$ long [86]. Srirangam et al. [15] and Anupam et al. [87] developed a tire-fluid-pavement interaction model to study the wet skid resistance and hydroplaning phenomena by introducing actual pavement surface morphologies. Tang et al. [78] presented an innovative tire-water-pavement interaction FE model to evaluate wet skid resistance under different rainfall intensities considering the effect of pavement geometric design, tire tread design, and various tire operating conditions. It was shown that the risk of safe driving significantly increases for a vehicle travelling at high speed under high rainfall intensities. It was also suggested that pavement with higher porosity and MPD values and a tire with a proper tread pattern are necessary for the increment of wet skid resistance. Such an FE tool with its capability to directly link rainfall intensity and wet skid resistance could, therefore, help pavement authorities to come up with effective engineering measures to ensure safe driving in the rainy season.

\subsubsection{Effect of Surface Contamination. Rubbing action be-} tween tire and road surface generates very fine abrasive compound made up of tire and road surface materials, which contributes a major portion of total contaminants along with wind-blown soil and debris. These contaminants that remain on the pavement and along the tire path affect the skid resistance by filling the small asperities available on the pavement surface. Studies show that the higher the contamination loading on the road surface is, the lower the micropores and hence the lower the skid resistance will be [88]. The addition of hard and fine-grained contaminants reduces measured skid resistance as it helps in polishing the aggregate surface, while the addition of hard but coarse-grained contaminants improves skid resistance as it helps in scratching and abrading the surface [89]. The thicker or the more viscous the contaminant, the greater the reduction in the pavement-tire friction. The grinding effect of hard contaminants, such as sand, accelerates the rate of wearing at the pavement surface [17]. Pavement surface contaminants such as water, snow, sand, silt, debris, and lubricating oil pose adverse effects on maintaining skid resistance. The contaminants that reduce the skid resistance value were, from the smallest to the greatest, water, sand, salt, and lubricating oil [90]. Filling of surface texture by contaminants can temporarily or permanently change the structure of the texture. Temporal filling of the surface texture usually causes dangerous situations during the first few minutes of rain and, in some cases, reduces the skid resistance by 50\% [89]. Alamdarlo and Hesami [91] measured the effect of the pavement porosity filling on skid resistance and found that, in the pavement with higher MTD (more than $0.85 \mathrm{~mm}$ ), till a percentage of surface porosity filled with contaminants of less than $10 \%$ of initial MTD, there is no significant change in skid number (less than 5\%). However, after a reduction of a further $10 \%$ of the MTD, the skid number reduces by another $15 \%$.

\section{General Discussion}

Factors affecting skid resistance and their trend of variation have been discussed briefly in previous sections. Table 1 highlights the critical factors affecting skid resistance, which 
emphasizes the relative importance of those factors and forms the basis of considering them while evaluating friction as a performance parameter. Efforts of authors in gathering information through field equipment and analysing and predicting suitable model for skid resistance and factors controlling it have been discussed, and concluding remarks of respective studies have been presented. At all stages of pavement life, the highway surface should have some sort of roughness to facilitate friction between vehicle and pavement surface. The texture of the pavement surface and its ability to resist the polishing effect of traffic load is of prime importance in providing necessary skid resistance. Different asphalt mix adds distinct texture to the pavement surface and offers different levels of skid resistance characteristics. It is important to understand that the surface which offers better riding comfort provides lesser resistance to skidding, so a compromise with riding comfort is made to ascertain pavement safety. The newly constructed surface has higher texture and provides better skid control; however, with increasing surface age, macrotexture reduces due to the polishing effect of surface aggregates subjected to cumulative load, and skid resistance reduces apparently. This section of this review manuscript discusses the effect of the vehicle and tire-related factors, among which vehicle speed and tire tread pattern are some of the few factors which are under road user control and shall be given due consideration to ensure better road safety. It has been seen that higher vehicle speed of around $100 \mathrm{~km} / \mathrm{hr}$ reduces skid resistance to a minimum value and poses serious concerns, especially in wet weather conditions. This section reviews the effect of environmental factors on skid resistance, among which ambient temperature, rain intensity or surface moisture, and contaminants are very critical and have significant contribution. Ambient temperature and rain intensity have a similar trend and as they increase, skid resistance decreases, with the difference that skid resistance variation with temperature is linear and variation with rain intensity is exponential. Few historical developments on these critical factors and the general trend of variation with skid resistance have been listed in Table 5 .

\section{Concluding Remarks}

Key parameters influencing skid resistance of asphalt pavements have been identified and reviewed. A brief overview of the variation of identified parameters with skid resistance at tire-pavement interface has been provided. This paper has provided an overview of the latest references on skid resistance variation not covered in previous studies. Papers reviewed in this study concentrate on factors controlling skid resistance and highlight critical factors which need more attention to ensure safety at the time of design of pavement itself or during its maintenance activities. Early studies on various critical factors controlling skid were limited to field computation of parameters, developing empirical relations, and proposing statistical trends of their variation and were time-consuming as well as labour-intensive. Empirical studies could offer a useful understanding of the mechanism of skid resistance and its influencing factors; however, the applicability of empirical relations is restricted as soon as there is a change in one of the relevant factors. The main objective of this paper was to investigate the effect of various pavement surface-related parameters, vehicle operation-related parameters, tire design parameters, and environmental factors on skid resistance. Although skid resistance available depends on several parameters as discussed, the three crucial factors contributing significantly to controlling skid resistance are surface texture, tire tread, and rain intensity. Firstly, the surface texture of the pavement shall be given due consideration at the time of design itself as rough surface provides high resistance against skidding. Research is being carried out to estimate the potential application of porous friction course over the top surface course of the pavement to increase road safety in terms of rolling resistance. Secondly, the use of higher tread depth of rolling tires shall be promoted for better skid resistance, and deep treaded tire also helps in channelling out accumulated water at the road surface. Finally, pavements shall be designed, constructed, and maintained in such a way to ensure minimum cross slope at every section as the presence of rainwater at road surface destroys the interfacial bond between tire and pavement and reduces resistance against skidding drastically. Hydroplaning is a very complex phenomenon to simulate as it needs coupling with tirepavement interaction model; however, with the advancement of finite element tools in recent years, researchers became able to simulate tire-fluid-pavement interaction more realistically.

\section{Challenges and Future Scope}

The authors find few challenges in the way of managing skid resistance and suggest few areas of future research interest based on this review article. (1) Available measuring devices in laboratories are not capable of simulating actual field conditions (e.g., surface texture, tire load and inflation pressure, and water film thickness). However, the advent of W/S and TDFA made it possible to simulate tire speed up to $100 \mathrm{~km} / \mathrm{hr}$, but this is very costly. Field measurement devices like ADHERA, RoadSTAR, and SCRIM are capable of addressing these concerns but are still away from most of the research agencies and pavement maintenance authorities. Thus, a cheap and reliable measuring device needs to be developed. (2) In recent years, the finite element technique has proved very effective due to its computational capabilities in skid resistance evaluation. Evaluation of skid resistance using computational and analytical tools is often far less expensive than conducting large-scale experiments. Further, FE models developed in last five years have the capability to (a) compute the hydroplaning speed at different slip ratios; (b) evaluate the effectiveness of MPD and different surface morphologies to combat loss of wet friction; and (c) examine the effect of water depth and tread pattern on skid resistance. The efficacy of these FE models in dealing with various factors affecting skid resistance lies in the complex modelling of tire and pavement submodel. Modelling the pavement as a nondeformable structure has been very common in many studies; however, it only allows us to 
quantify tire-pavement friction from the tire perspective ignoring the fact that deformable behaviour of the pavement structure may ultimately influence the friction value to some extent. Therefore, it is necessary to take pavement deformation into account for better realization of skid resistance. (3) Laboratory and field evaluation of skid resistance are independent in nature and need harmonization in measurement to supplement the designing method, based on the skid resistance of asphalt pavement.

\section{Conflicts of Interest}

The authors declare that they have no conflicts of interest.

\section{Acknowledgments}

This review work was supported by the Ministry of Education, Government of India (MHRD Fellowship to $\mathrm{Mr}$. Abhinav Kumar). The authors would also like to thank the Indian Institute of Technology (Banaras Hindu University), Varanasi, for facilitating the review study.

\section{References}

[1] G. P. Ong and T. F. Fwa, "Prediction of wet-pavement skid resistance and hydroplaning potential," Transportation Research Record: Journal of the Transportation Research Board, vol. 2005, no. 1, pp. 160-171, 2007.

[2] J. M. Pardillo Mayora and R. Jurado Piña, “An assessment of the skid resistance effect on traffic safety under wet-pavement conditions," Accident Analysis \& Prevention, vol. 41, no. 4, pp. 881-886, 2009.

[3] ASTM E (1845), Standard Practice for Calculating Pavement Macrotexture Mean Profile Depth, ASTM International, Annual Book of ASTM Standards West, Conshohocken, PA, USA, 2015.

[4] A. Dunford, "Friction and the texture of aggregate particles used in the road surface course," Ph. D. Thesis, Doctoral dissertation, University of Nottingham, Nottingham, UK, 2013.

[5] F. G. Praticò and R. Vaiana, "A study on the relationship between mean texture depth and mean profile depth of asphalt pavements," Construction and Building Materials, vol. 101, pp. 72-79, 2015.

[6] D. A. Noyce, H. U. Bahia, J. M. Yambo, and G. Kim, Incorporating Road Safety into Pavement Management: Maximizing Asphalt Pavement Surface Friction for Road Safety Improvements. Draft Literature Review and State Surveys, Midwest Regional University Transportation Center (UMTRI), Madison, WI, USA, 2005.

[7] S. Li, K. Zhu, S. Noureldin, and D. Harris, "Identifying friction variations with the standard smooth tire for network pavement inventory friction testing," Transportation Research Record: Journal of the Transportation Research Board, vol. 1905, no. 1, pp. 157-165, 2005.

[8] T. Chelliah, P. Stephanos, T. Smith, and B. Kochen, "Developing a design policy to improve pavement surface characteristics," in Proceedings of the Pavement Evaluation Conference, Roanoke, Virginia, USA, 2002.

[9] D. Kuemmel, R. Sonntag, J. Crovetti, Y. Becker, J. R. Jaeckel, and A. Satanovsky, "Main project report: noise and texture on PCC pavements," WI/SPR-08-99, 2000.
[10] M. Mohanty and A. Gupta, "Investigation of adolescent accident predictive variables in hilly regions," International Journal of Injury Control and Safety Promotion, vol. 23, no. 3, pp. 291-301, 2016.

[11] J. S. Kuttesch, Quantifying the Relationship between Skid Resistance and Wet Weather Accidents for Virginia Data, Doctoral dissertation, Virginia Tech, DC, USA, 2004.

[12] M. Saplioglu, E. Yuzer, B. Aktas, and E. Eriskin, "Investigation of the skid resistance at accident occurred at urban intersections," Journal of Traffic and Transportation Engineering, vol. 1, no. 12, 2013.

[13] J. Pitaksringkarn, L. Tanwanichkul, and K. Yamthale, "A correlation between pavement skid resistance and wetpavement-related accidents in Thailand," in MATEC Web of Conferencesvol. 192, EDP Sciences, Article ID 02049, 2018.

[14] M. Mohanty and A. Gupta, "Factors affecting road crash modeling," Journal of transport literature, vol. 9, no. 2, pp. 15-19, 2015.

[15] S. K. Srirangam, K. Anupam, A. Scarpas, and C. Kasbergen, "Development of a thermomechanical tyre-pavement interaction model," International Journal of Pavement Engineering, vol. 16, no. 8, pp. 721-729, 2015.

[16] B. Choubane, C. R. Holzschuher, and S. Gokhale, "Precision of locked-wheel testers for measurement of roadway surface friction characteristics," Transportation Research Record: Journal of the Transportation Research Board, vol. 1869, no. 1, pp. 145-151, 2004.

[17] J. W. Hall, K. L. Smith, L. Titus-Glover, J. C. Wambold, T. J. Yager, and Z. Rado, "Guide for pavement friction," Final Report for NCHRP Project, vol. 1, p. 43, 2009.

[18] M. M. Kanafi and A. J. Tuononen, "Application of threedimensional printing to pavement texture effects on rubber friction," Road Materials and Pavement Design, vol. 18, no. 4, pp. 865-881, 2017.

[19] S. Kouchaki, H. Roshani, J. A. Prozzi, N. Z. Garcia, and J. B. Hernandez, "Field investigation of relationship between pavement surface texture and friction," Transportation Research Record: Journal of the Transportation Research Board, vol. 2672, no. 40, pp. 395-407, 2018.

[20] B. Hofko, H. Kugler, G. Chankov, and R. Spielhofer, "A laboratory procedure for predicting skid and polishing resistance of road surfaces," International Journal of Pavement Engineering, vol. 20, no. 4, pp. 439-447, 2019.

[21] M. Yu, Z. You, G. Wu, L. Kong, C. Liu, and J. Gao, "Measurement and modeling of skid resistance of asphalt pavement: a review," Construction and Building Materials, vol. 260, Article ID 119878, 2020.

[22] G. Descornet, B. Schmidt, M. Boulet et al., HERMES Project (Harmonization of European Routine and Research Measuring Equipment for Skid Resistance, Transportation Research Board, USA, 2006.

[23] M.-T. Do and P. Roe, Report on State-of-the-Art of Test Methods TYROSAF Project Deliverable D04, p. 89, 2009.

[24] T. Andriejauskas, V. Vorobjovas, and V. Mielonas, "Evaluation of skid resistance characteristics and measurement methods," in Proceedings of the International Conference on Environmental Engineering. ICEE, vol. 9, p. 1, May 2014.

[25] R. B. Kogbara, E. A. Masad, E. Kassem, A. Scarpas, and K. Anupam, "A state-of-the-art review of parameters influencing measurement and modeling of skid resistance of asphalt pavements," Construction and Building Materials, vol. 114, pp. 602-617, 2016.

[26] F. G. Praticò and A. Astolfi, "A new and simplified approach to assess the pavement surface micro- and macrotexture," 
Construction and Building Materials, vol. 148, pp. 476-483, 2017.

[27] J. J. Henry, Evaluation of Pavement Friction Characteristics, Vol. 291, Transportation Research Board, Washington, DC, USA, 2000.

[28] R. F. Smiley and W. B. Horne, Mechanical Properties of Pneumatic Tires with Special Reference to Modern Aircraft Tires, Vol. 64, National Aeronautics and Space Administration, Washington, DC, USA, 1958.

[29] D. Chen, S. Han, A. Ye, X. Ren, W. Wang, and T. Wang, "Prediction of tire-pavement friction based on asphalt mixture surface texture level and its distributions," Road Materials and Pavement Design, vol. 21, no. 6, pp. 1545-1564, 2020.

[30] H. Wang and Z. Wang, "Evaluation of pavement surface friction subject to various pavement preservation treatments," Construction and Building Materials, vol. 48, pp. 194-202, 2013.

[31] J. N. Meegoda and S. Gao, "Evaluation of pavement skid resistance using high speed texture measurement," Journal of Traffic and Transportation Engineering, vol. 2, no. 6, pp. 382-390, 2015.

[32] R. M. Larson, Consideration of Tire/pavement Friction/texture Effects on Pavement Structural Design and Materials Mix Design, Office of Pavement Technology, Suite, Ames, IA, 1999.

[33] Q. J. Li, Y. Zhan, G. Yang, D. M. Pittenger, and K. C. Wang, "3D Characterization of aggregates for pavement skid resistance," Journal of Transportation Engineering, Part B: Pavements, vol. 145, no. 2, Article ID 04019002, 2019.

[34] P. A. Serigos, A. De Fortier Smit, and J. A. Prozzi, "Incorporating surface microtexture in the prediction of skid resistance of flexible pavements," Transportation Research Record: Journal of the Transportation Research Board, vol. 2457, no. 1, pp. 105-113, 2014.

[35] D. Chen, Study on two-dimension image-based texture analysis method and prediction of skid-resistance \& tirel pavement noise reduction of HMA (Doctoral dissertation, Chang'an University, Thesis (Ph.D.), 2015.

[36] B. Guan, J. Wu, C. Xie, J. Fang, H. Zheng, and H. Chen, "Influence of macrotexture and microtexture on the skid resistance of aggregates," Advances in Materials Science and Engineering, vol. 2018, Article ID 1437069, 9 pages, 2018.

[37] G. W. Flintsch, K. K. McGhee, E. de León Izeppi, and S. Najafi, The Little Book of Tire Pavement Friction, Pavement Surface Properties Consortium, Virginia Tech, DC, USA, 2012.

[38] X. Xie, C. Wang, D. Wang, Q. Fan, and M. Oeser, "Evaluation of polishing behavior of fine aggregates using an accelerated polishing machine with real tires," Journal of Transportation Engineering, Part B: Pavements, vol. 145, no. 2, Article ID 04019015, 2019.

[39] G. McQuaid, P. Millar, D. Woodward, and S. Friel, "Use of close-range photogrammetry to assess the micro-texture of asphalt surfacing aggregate," International Journal of Pavements Conference, 2013.

[40] W. B. Horne, "Status of runway slipperiness research," Transportation Research Record, vol. 624, pp. 95-121, 1977.

[41] S. W. Forster, "Pavement micro-texture and its relation to skid resistance," Transportation Research Record, vol. 1215, pp. 151-164, 1989.

[42] D. L. Bloem, Skid-resistance-the Role of Aggregates and Other Factors, National Sand \& Gravel Assoc Circulars, Transportation Research Board, USA, 1971.
[43] Y. Liu, T. F. Fwa, and Y. S. Choo, "Effect of surface macrotexture on skid resistance measurements by the British Pendulum Test," Journal of Testing and Evaluation, vol. 32, no. 4, pp. 304-309, 2004.

[44] M. A. Khasawneh, "Macrotexture characterisation of laboratory-compacted hot-mix asphalt specimens using a new asphalt polishing machine," Road Materials and Pavement Design, vol. 19, no. 2, pp. 400-416, 2018.

[45] U. Sandberg, Influence of Road Surface Texture on Traffic Characteristics Related to Environment, Economy and Safety: A State-Of-The-Art Study Regarding Measures and Measuring Methods, VTI notat 53A-1997, Linköping, Sweden, 1998.

[46] K. Anupam, S. K. Srirangam, A. Scarpas, and C. Kasbergen, "Influence of temperature on tire-pavement friction," Transportation Research Record: Journal of the Transportation Research Board, vol. 2369, no. 1, pp. 114-124, 2013.

[47] B. Zheng, X. Huang, W. Zhang, R. Zhao, and S. Zhu, "Adhesion characteristics of tire-asphalt pavement interface based on a proposed tire hydroplaning model," Advances in Materials Science and Engineering, vol. 2018, Article ID 5916180, 12 pages, 2018.

[48] A. Ongel, Q. Lu, and J. Harvey, "Frictional properties of asphalt concrete mixes," Proceedings of the Institution of Civil Engineers-Transport, vol. 162, no. 1, pp. 19-26, 2009.

[49] I. M. Asi, "Evaluating skid resistance of different asphalt concrete mixes," Building and Environment, vol. 42, no. 1, pp. 325-329, 2007.

[50] J. Shupe, Pavement Slipperiness, McGraw-Hill Book Company, New York, NY, USA, 1960.

[51] M. Magnoni, F. Giustozzi, E. Toraldo, and M. Crispino, "Evaluation of the effect of aggregate mineralogy and geometry on asphalt mixture friction," Journal of Civil \& Environmental Engineering, vol. 6, no. 223, p. 2, 2016.

[52] T. R. West, J. C. Choi, D. W. Bruner, H. J. Park, and K. H. Cho, "Evaluation of dolomite and related aggregates used in bituminous overlays for Indiana pavements," Transportation Research Record: Journal of the Transportation Research Board, vol. 1757, no. 1, pp. 137-147, 2001.

[53] R. Y. Liang and L. L. Chyi, Polishing and Friction Characteristics of Aggregates Produced in Ohio, Ohio department of transportation, Columbus, OH, USA, 2000.

[54] G. W. Flintsch, K. K. McGhee, and E. de Leon, "Field validation of macrotexture-based hot mix asphalt segregation detection methods," Journal of the Association of Asphalt Paving Technologists, vol. 74, 2005.

[55] C. Kennedy, A. Young, and I. Butler, "Measurement of skidding resistance and surface texture and the use of results in the United Kingdom," in Surface characteristics of Roadways: International research and Technologiesvol. 87, ASTM International, 1990.

[56] A. Harald, "Skid resistance and road surface texture," Symposium: Surface Characteristics of Roadways, 1990.

[57] G. R. Dewey, A. C. Robords, B. T. Armour, and R. Muethel, Aggregate Wear and Pavement FrictionTransportation Research Board, Annual Meeting CD-ROM, Washington, DC,USA, 2001.

[58] D. C. Colony, "Overview of skid resistance on Ohio pavements," Journal of Transportation Engineering, vol. 111, no. 5, pp. 546-560, 1985.

[59] D. Hogervorst, "Some properties of crushed stone for road surfaces," Bulletin of the International Association of Engineering Geology, vol. 10, no. 1, pp. 59-64, 1974. 
[60] W. H. Skerritt, Aggregate Type and Traffic Volume as Controlling Factors in Bituminous Pavement Friction, Transportation Research Record, (1418), Albany, NY, USA, 1993.

[61] P. G. Roe, A. R. Parry, and H. E. Viner, High and Low Speed Skidding Resistance: The Influence of Texture Depth, Transport Research Laboratory, Wokingham, UK, 1998.

[62] P. Colonna, N. Berloco, P. Intini, A. Perruccio, and V. Ranieri, "Evaluating skidding risk of a road layout for all types of vehicles," Transportation Research Record: Journal of the Transportation Research Board, vol. 2591, no. 1, pp. 94102, 2016.

[63] X. Hu, A. N. M. Faruk, J. Zhang, M. I. Souliman, and L. F. Walubita, "Effects of tire inclination (turning traffic) and dynamic loading on the pavement stress-strain responses using 3-D finite element modeling," International Journal of Pavement Research and Technology, vol. 10, no. 4, pp. 304-314, 2017.

[64] G. Maycock, "Second paper: studies on the skidding resistance of passenger-car tyres on wet surfaces," Proceedings Institution of Mechanical Engineers: Automobile Division, vol. 180, no. 1, pp. 122-157, 1965.

[65] W. Horne, "Pavement grooving-a means of increasing skid resistance," Materials Research and Standards, vol. 8, no. 8, p. 35, 1968.

[66] W. Gengenbach, "Experimental investigation of tires on a wet roadway," ATZ, vol. 70, no. 9, 1968.

[67] G. C. Staughton, The Effect of Tread Pattern Depth on Skidding Resistance, Transport and Road research department, Washington, Berkshire, UK, 1970.

[68] A. R. Woodside and D. H. Woodward, Wet Skid Resistance. Highways: The Location, Design, Construction, and Maintenance of Road Pavements, Taylor \& Francis, Florida, NY, USA, 2002.

[69] J. J. Henry and K. Saito, Skid-Resistance Measurements with Blank and Ribbed Test Tires and Their Relationship to Pavement Texture (No. HS-037 872), Transportation Research Board, Washington, DC, USA, 1983.

[70] A. Suyabodha, "A relationship between tire pressure and rolling resistance force under different vehicle speed," in MATEC Web of Conferencesvol. 108, EDP Sciences, Article ID 12004, 2017.

[71] L. G. Fuentes, Investigation of the Factors Influencing Skid Resistance and the International Friction Index, Graduate Thesis, University of South Florida, Tallahassee, FL, USA, 2009.

[72] C. Plati and M. Pomoni, "Impact of traffic volume on pavement macrotexture and skid resistance long-term performance," Transportation Research Record: Journal of the Transportation Research Board, vol. 2673, no. 2, pp. 314-322, 2019.

[73] R. Hosking, Road Aggregates and Skidding, Majesty Stationary Office, London, UK, 1992.

[74] M. P. McDonald, L. G. Crowley, and R. E. Turochy, "Determining the causes of seasonal variation in pavement friction," Transportation Research Record: Journal of the Transportation Research Board, vol. 2094, no. 1, pp. 128-135, 2009.

[75] E. Baran, "Temperature influences on skid resistance measurement," International Surface Friction Conference, vol. 2011, 2011.

[76] S. G. Jahromi, S. M. R. Mortazavi, S. Voussough, and L. Yingjian, "Evaluation of pavement temperature on skid frictional of asphalt concrete surface," International Journal of Pavement Engineering, vol. 12, no. 1, pp. 47-58, 2011.
[77] S. M. Bazlamit and F. Reza, "Changes in asphalt pavement friction components and adjustment of skid number for temperature," Journal of Transportation Engineering, vol. 131, no. 6, pp. 470-476, 2005.

[78] T. Tang, K. Anupam, C. Kasbergen, A. Scarpas, and S. Erkens, "A finite element study of rain intensity on skid resistance for permeable asphalt concrete mixes," Construction and Building Materials, vol. 220, pp. 464-475, 2019.

[79] D. F. Moore, "The friction and lubrication of elastomers," vol. 9, Pergamon, 1972.

[80] P. W. Jayawickrama and B. Thomas, "Correction of field skid measurements for seasonal variations in Texas," Transportation Research Record: Journal of the Transportation Research Board, vol. 1639, no. 1, pp. 147-154, 1998.

[81] M. Mohanty and A. Gupta, "Review of recent trends in road accident modelling," Indian highways, Journal of Indian Roads Congress, vol. 42, no. 12, pp. 3-7, 2014.

[82] J. G. Rose and B. M. Gallaway, "Water depth influence on pavement friction," Transportation Engineering Journal of ASCE, vol. 103, no. 4, pp. 491-506, 1977.

[83] J. Wambold, J. Henry, and R. Hegmon, "Skid resistance of wet-weather accident sites," in The Tire Pavement Interfacevol. 47West Conshohocken, PA, USA, ASTM International, 1986.

[84] A. Gupta and A. Kumar, "Comparative structural analysis of flexible pavements using finite element method," International Journal on Pavement Engineering \& Asphalt Technology, vol. 15, no. 1, pp. 11-19, 2014.

[85] D. W. Harwood, R. R. Blackburn, and A. D. St John, "Evaluation of accident rate-skid number relationships for a nationwide sample of highway sections," Transportation Research Record, vol. 624, pp. 142-150, 1987.

[86] G. G. Hayes, D. L. Ivey, and B. M. Gallaway, Hydroplaning, Hydrodynamic Drag, and Vehicle Stability, Frictional Interaction of Tire and Pavement. ASTM International, West Conshohocken, PA, USA, 1983.

[87] K. Anupam, S. Santosh Kumar, C. Kasbergen, A. Scarpas, and M. Kane, "Finite element framework for the computation of runway friction of aircraft tires," Transportation Research Record: Journal of the Transportation Research Board, vol. 2641, no. 1, pp. 126-138, 2017.

[88] R. B. Shakely, J. J. Henry, and R. J. Heinsohn, "Effects of pavement contaminants on skid resistance," Transportation Research Record, vol. 788, pp. 23-28, 1980.

[89] D. J. Wilson, The Effect of Rainfall and Contaminants on Road Pavement Skid Resistance, Zealand transport agency, Wellingtonm, New Zealand, 2013.

[90] A. S. Lubis, Z. A. Muis, and E. M. Gultom, "The effect of contaminant on skid resistance of pavement surface," in IOP Conference Series: Earth and Environmental Sciencevol. 126, no. 1, IOP Publishing, Article ID 012040, 2018.

[91] M. N. Alamdarlo and S. Hesami, "Measuring the effect of pavement porosity filling on skid resistance by numerical model and field test," Measurement, vol. 152, Article ID 107269, 2020.

[92] R. B. Kogbara, E. A. Masad, K. Anupam, and A. Scarpas, "GripTester measurements and texture-friction relationship," in Proceedings of the Advances in Materials and Pavement Prediction: Papers from the International Conference on Advances in Materials and Pavement Performance Prediction (AM3P 2018), pp. 287-291, CRC Press, Doha, Qatar, April 2018.

[93] Y. Peng, J. Q. Li, Y. Zhan, K. C. Wang, and G. Yang, "Finite element method-based skid resistance simulation using in- 
situ 3D pavement surface texture and friction data," Materials, vol. 12, no. 23, Article ID 3821, 2019.

[94] Y. Zhou, H. Zhu, W. Zhang, X. Zuo, Y. Li, and J. Yang, "Influence of surface roughness on the friction property of textured surfaces," Advances in Mechanical Engineering, vol. 7, no. 2, Article ID 1687814014568500, 2015.

[95] D. C. Mahone and W. C. Sherwood, The Effect of Aggregate Type and Mix Design on the Wet Skid Resistance of Bituminous Pavement: recommendations for Virginia's Wet Accident Reduction Program (No. FHWA/VA-96-R10), Virginia Transportation Research Council, Charlottesville, VA, US, 1995.

[96] E. Masad, A. Rezaei, A. Chowdhury, and P. Harris, Predicting Asphalt Mixture Skid Resistance Based on Aggregate Characteristics (No. FHWA/TX-09/0-5627-1), Dept. of Transportation. Research and Technology Implementation Office, Texas, 2009.

[97] C. Kangkhajitre and K. Kanitpong, "Effect of aggregate characteristics on texture and skid resistance of asphalt pavement surface," Journal of the Eastern Asia Society for Transportation Studies, vol. 9, pp. 1210-1224, 2011.

[98] M. Kane, D. Zhao, M. T. Do, E. Chailleux, and F. DeLalarrard, "Exploring the ageing effect of binder on skid resistance evolution of asphalt pavement," Road Materials and Pavement Design, vol. 11, no. 1, pp. 543-557, 2010.

[99] L. Zhang, G. P. Ong, and T. F. Fwa, "Developing an analysis framework to quantify and compare skid resistance performance on porous and nonporous pavements," Transportation Research Record: Journal of the Transportation Research Board, vol. 2369, no. 1, pp. 77-86, 2013.

[100] S. M. Oh, D. R. Ragland, and C. Y. Chan, Evaluation of Traffic and Environment Effects on Skid Resistance and Safety Performance of Rubberized Open-Grade Asphalt Concrete (No. UCB-ITS-PRR-2010-14), California PATH Research Report, University of California, Berkeley, CA, USA, 2010.

[101] F. Reza and S. M. Bazlamit, "Skid resistance variation with temperature," in Proceedings of the Conference on mechanics and materials, Baton Rouge Louisiana, USA, 2005.

[102] M. C. Leu and J. J. Henry, "Prediction of skid resistance as a function of speed from pavement texture measurements," Transportation Research Record, vol. 666, pp. 7-13, 1978.

[103] F. Sun, Y. Hou, L. Wang, L. Huang, and Z. Qian, "A molecular dynamics (MD) simulation on tire-aggregate friction," International Journal of Pavement Research and Technology, vol. 10, no. 4, pp. 343-351, 2017.

[104] T. Tang, K. Anupam, C. Kasbergen, R. Kogbara, A. Scarpas, and E. Masad, "Finite element studies of skid resistance under hot weather condition," Transportation Research Record: Journal of the Transportation Research Board, vol. 2672, no. 40, pp. 382-394, 2018.

[105] S. K. Srirangam, K. Anupam, C. Kasbergen, and A. Scarpas, "Analysis of asphalt mix surface-tread rubber interaction by using finite element method," Journal of Traffic and Transportation Engineering, vol. 4, no. 4, pp. 395-402, 2017.

[106] P. Cao, X. Yan, X. Bai, and C. Yuan, "Effects of contaminants on skid resistance of asphalt pavements," in Proceedings of the Traffic and Transportation Studies 2010, pp. 1341-1351, Reston, VA, USA, 2010.

[107] C. Changyong, Skid Resistance and Hydroplaning Analysis of Asphalt Mix Surface-Tread Rubber Interaction by Using Finite Element Method Analysis of Rib Truck Tires, Department of Civil and Environmental Engineering, Singapore, 2010. 